\title{
Enhanced Thermoelectric Performance by the Strong Phonon Scattering at the Heterogeneous Interfaces of $\mathrm{Mg}_{2} \mathrm{Sn} / \mathrm{Mg}_{3} \mathrm{Sb}_{2}$ High-content Nanocomposite
}

Yongbin Zhu ${ }^{1,2}$, Bing $\mathrm{Han}^{2}$, Zhijia $\mathrm{Han}^{2}$, Feng Jiang ${ }^{2}$, Xinzhi $\mathrm{Wu}^{2}$, Cheng-Gong $\mathrm{Han}^{2}$, Yonghong Deng ${ }^{2}$, Weishu Liu ${ }^{2,3 *}$

${ }^{1}$ School of Materials Science and Engineering, Harbin Institute of Technology, Harbin 150001, China

${ }^{2}$ Department of Materials Science and Engineering, Southern University of Science and Technology, Shenzhen 518055, China

${ }^{3}$ Key Laboratory of Energy Conversion and Storage Technologies (Ministry of Education), Southern University of Science and Technology, Shenzhen, 518055, China

*Corresponding author: liuws@sustech.edu.cn 


\section{Supporting Information}

\section{Section SA: Phase compositions}

According to the pseudo-binary phase diagram $\mathrm{Mg}_{2} \mathrm{Sn}_{-} \mathrm{Mg}_{3} \mathrm{Sb}_{2}$ in Figure S1, a series of $\mathrm{Mg}_{2} \mathrm{Sn} / \mathrm{Mg}_{3} \mathrm{Sb}_{2}-x$ Te HCnCs $(x=0,0.01,0.02,0.03$, and 0.04) were in situ synthesized by the ball milling and hot pressing, which were identified as the composite of hexagonal $\mathrm{Mg}_{3} \mathrm{Sb}_{2}$ (JCPDS: 71-0404) phase and cubic $\mathrm{Mg}_{2} \mathrm{Sn}$ (JCPDS: 07-0274) without any detectable impurity by the X-ray diffraction (XRD) in Figure S2. Figure S2b shows the calculated lattice parameters of $\mathrm{Mg}_{2} \mathrm{Sn}$ and $\mathrm{Mg}_{3} \mathrm{Sb}_{2}$ components based on the Rietveld refinement of the XRD patterns. The Te dopant didn't change the lattice parameter. If raw materials (i.e., elemental $\mathrm{Mg}, \mathrm{Sn}$, and $\mathrm{Sb}$ ) spontaneously formed composites consisting of stoichiometric $\mathrm{Mg}_{2} \mathrm{Sn}$ and $\mathrm{Mg}_{3} \mathrm{Sb}_{2}$ phases, the composites should comprise 36.89 vol.\% $\mathrm{Mg}_{2} \mathrm{Sn}$ and 63.11 vol. $\% \mathrm{Mg}_{3} \mathrm{Sb}_{2}$. However, the actual phase fraction of $\mathrm{Mg}_{1.85} \mathrm{Sn}_{0.39} \mathrm{Sb}_{0.61} / \mathrm{Mg}_{3.28} \mathrm{Sb}_{1.85} \mathrm{Sn}_{0.15} \mathrm{HCnCs}$ was estimated to be 54.15 vol. $\% \mathrm{Mg}_{2} \mathrm{Sn}$ and 45.85 vol.\% $\mathrm{Mg}_{3} \mathrm{Sb}_{2}$ by Rietveld refinement as shown in Figure S3. Besides, compared with the standard peak position of the JCPDS card, the diffraction peaks of the $\mathrm{Mg}_{2} \mathrm{Sn}$-phase severely shift to a higher angle (e.g., $\Delta_{2 \theta}^{+}=0.233^{\circ}$ for maximum diffraction peak (111)) because of the lattice shrink caused by the self-compensation $\mathrm{Mg}$ vacancy via $\mathrm{Sb}$ dissolving into $\mathrm{Mg}_{2} \mathrm{Sn}$. ${ }^{(1)}$ However, the XRD peaks of the $\mathrm{Mg}_{3} \mathrm{Sb}_{2}$ shift a little (e.g., $\Delta_{2 \theta}^{+}=0.032^{\circ}$ for maximum diffraction peak (011)).

\section{Section SB: Mechanical properties}

Figure S4a shows the Vickers hardness $H_{v}$ for the as-fabricated $\mathrm{Mg}_{2} \mathrm{Sn} / \mathrm{Mg}_{3} \mathrm{Sb}_{2}-x$ Te HCnCs $(x=0,0.01,0.02,0.03$, and 0.04$)$ in the range of 1.9-2.1 $\mathrm{GPa}$, presenting a weak decrease with increasing Te content. While the fracture toughness-displacement curve of $\mathrm{Mg}_{2} \mathrm{Sn} / \mathrm{Mg}_{3} \mathrm{Sb}_{2}-0.02 \mathrm{Te} \mathrm{HCnC}$ exhibits a typical characteristic of brittle fracture, where the complete failure happens at the peak load with an immediate drop in the loading force, ${ }^{(2)}$ as shown in Figure S4b. The fracture toughness $K_{\mathrm{IC}}$ (Figure S4c) firstly increase from $2.32 \mathrm{MPa} \mathrm{m}^{1 / 2}$ for $x=0$ to $2.99 \mathrm{MPa}$ $\mathrm{m}^{1 / 2}$ for $x=0.01$ and then decrease to $2.33 \mathrm{MPa} \mathrm{m}^{1 / 2}$ for $x=0.03$. Figure S4d depicts 


\section{Supporting Information}

the fracture toughness against Young's modulus $(E)$ of all the $\mathrm{Mg}_{2} \mathrm{Sn} / \mathrm{Mg}_{3} \mathrm{Sb}_{2}-x \mathrm{Te}$ $\mathrm{HCnCs}$, also including other typical thermoelectric materials: $\mathrm{Bi}_{2} \mathrm{Te}_{3},{ }^{(3)-(4)} \mathrm{PbTe},{ }^{(5)}$ $\mathrm{MgAgSb},{ }^{(6)} \mathrm{CoSb}_{3},{ }^{(7)} \mathrm{SiGe},{ }^{(8)} \mathrm{CaMnO}_{3},{ }^{(9)} \mathrm{Mg}_{2} \mathrm{Sn},{ }^{(10)}$ and $\mathrm{Mg}_{3} \mathrm{Sb}_{2}{ }^{(11)}$ for comparison. Among these, the as-fabricated $\mathrm{Mg}_{2} \mathrm{Sn} / \mathrm{Mg}_{3} \mathrm{Sb}_{2}-x$ Te $\mathrm{HCnCs}$ possess maximum fracture toughness values and relatively low Young's modulus, which is close to that of a single $\mathrm{Mg}_{3} \mathrm{Sb}_{2}$ phase. For example, all $\mathrm{Mg}_{2} \mathrm{Sn} / \mathrm{Mg}_{3} \mathrm{Sb}_{2}-x$ Te HCnCs show a $K_{\mathrm{IC}}$ in the range of 2.3-3.0 $\mathrm{MPa} \mathrm{m} \mathrm{m}^{1 / 2}$, higher than single $\mathrm{Mg}_{2} \mathrm{Sn}\left(1.25 \mathrm{MPa} \mathrm{m}{ }^{1 / 2}\right.$ ), single $\mathrm{Mg}_{3} \mathrm{Sb}_{2}\left(2.19 \mathrm{MPa} \mathrm{m}{ }^{1 / 2}\right)$, and most of the known thermoelectric materials, such as $\operatorname{PbTe}\left(0.34 \mathrm{MPa} \mathrm{m}^{1 / 2}\right)$, Skutterudites (1.5 $\left.\mathrm{MPa} \mathrm{m}^{1 / 2}\right)$, and SiGe $\left(1.0 \mathrm{MPa} \mathrm{m}^{1 / 2}\right)$.

Measurement: The elastic moduli can be estimated from the measured sound velocity as follows, ${ }^{(12)(13)}$

$$
\begin{gathered}
C_{11}=d v_{l}^{2} \\
G=d v_{t}^{2} \\
E=d \frac{3 v_{t}^{2} v_{l}^{2}-4 v_{t}^{4}}{v_{l}^{2}-v_{t}^{2}} \\
v=\frac{E}{2 G}-1 \\
B=\frac{E}{3(1-2 v)}
\end{gathered}
$$

Where $d$ is the bulk density, $v_{l}$, and $v_{t}$ are the longitudinal and transverse velocities measured by utilizing a commercial resonant ultrasound spectroscopy (RUS) apparatus, $C_{11}$ is the longitudinal modulus, $G$ is the shear modulus, $E$ is Young's modulus, $v$ is the Poisson's ratio, and $B$ is the bulk modulus. The Vickers hardness $(H v)$ measurement at room temperature was carried out using a hardness tester (HX-1000TM/LCD, TaiMing, China) with an indentation force of $2.94 \mathrm{~N}$ maintained for $15 \mathrm{~s}$. By measuring the diagonal length, the $H v$ values are estimated as follows. ${ }^{(14)]}$

$$
H_{v}=\frac{1.8544 F_{0}}{(2 a)^{2}}
$$

Where $F_{0}$ is the applied load, and $2 a$ is the average diagonal length of the indentation 


\section{Supporting Information}

impression. The fracture toughness was measured according to the single-edge notched beam (SENM) method. SENM samples with dimensions of $3 \mathrm{~mm} \times 2 \mathrm{~mm} \times$ $11 \mathrm{~mm}$ and a pre-crack size of $0.3 \mathrm{~mm} \times 1.2 \mathrm{~mm}$ were carefully cut and polished for the test, which was carried out at room temperature with a crosshead speed of 0.05 $\mathrm{mm} \mathrm{min}^{-1}$ on an MTS universal test machine (E44.104, MTS, China). The $K_{\mathrm{IC}}$ can be derived from the following equations by recording the maximum fracture force $(F):(15)]$

$$
\begin{gathered}
K_{I C}=\frac{F S}{B W^{3 / 2}} f\left(\frac{c}{W}\right) \\
f\left(\frac{c}{W}\right)=2.9\left(\frac{c}{W}\right)^{1 / 2}-4.6\left(\frac{c}{W}\right)^{3 / 2}+21.8\left(\frac{c}{W}\right)^{5 / 2} \\
-37.6\left(\frac{c}{W}\right)^{7 / 2}+38.7\left(\frac{c}{W}\right)^{9 / 2}
\end{gathered}
$$

Where $F, S, B, W, c$ are respectively the breaking load, a supporting span of the fixture $(12 \mathrm{~mm})$, and the sample's height, width, and pre-crack length. $f(c / W)$ is the stress-intensity shape fact.

\section{Section SC: The details of the EMA model fitting}

A general Maxwell-Garnett type effective medium approximation (EMA) was used to investigate the thermal conductivity of as-fabricated $\mathrm{Mg}_{2} \mathrm{Sn} / \mathrm{Mg}_{3} \mathrm{Sb}_{2} \mathrm{HCnC}$. To simulate reasonably the experimental lattice thermal conductivity $\kappa_{\text {lat }}$, it is crucial to choose the right lattice thermal conductivities of the matrix and dispersed phase. Based on the results of the chemical distribution of $\mathrm{Mg}_{2} \mathrm{Sn} / \mathrm{Mg}_{3} \mathrm{Sb}_{2} \mathrm{HCnCs}$ (Figure S4 and Table S1), the average chemical composition of the matrix and dispersed phase are $\mathrm{Mg}_{1.85} \mathrm{Sn}_{0.39} \mathrm{Sb}_{0.61}$ and $\mathrm{Mg}_{3.28} \mathrm{Sb}_{1.85} \mathrm{Sn}_{0.15}$, respectively. For the matrix, its lattice thermal conductivity $\kappa_{\mathrm{m}}$ select the value of $\mathrm{Mg}_{2-\delta} \mathrm{Sn}_{0.5} \mathrm{Sb}_{0.5}{ }^{(1)}$. Because the lattice thermal conductivity $\kappa_{\text {lat }}$ is almost unchanged as the solution of $\mathrm{Sb}$ in $\mathrm{Mg}_{2} \mathrm{Sn}$ increases from 40 at.\% to 50 at.\% (Figure S6), it is reasonable to assume that the $\kappa_{\text {lat }}$ of $\mathrm{Mg}_{2-\delta} \mathrm{Sn}_{0.4} \mathrm{Sb}_{0.6}$ is similar to that of $\mathrm{Mg}_{2-\delta} \mathrm{Sn}_{0.5} \mathrm{Sb}_{0.5}$. According to the Callaway 


\section{Supporting Information}

model, the phonon scattering from the $\mathrm{Sn}_{\mathrm{Sb}}$ defects should be negligible because of similar atomic mass and radius between the $\mathrm{Sn}(\mathrm{M}=118.71, r=1.41 \AA)$ and $\mathrm{Sb}(\mathrm{M}=$ 121.76, $r=1.45 \AA$,). Therefore, the lattice thermal conductivity $\kappa_{\mathrm{p}}$ of dispersed phase can take equivalently to the data of pure $\mathrm{Mg}_{3} \mathrm{Sb}_{2} \cdot{ }^{(16)}$

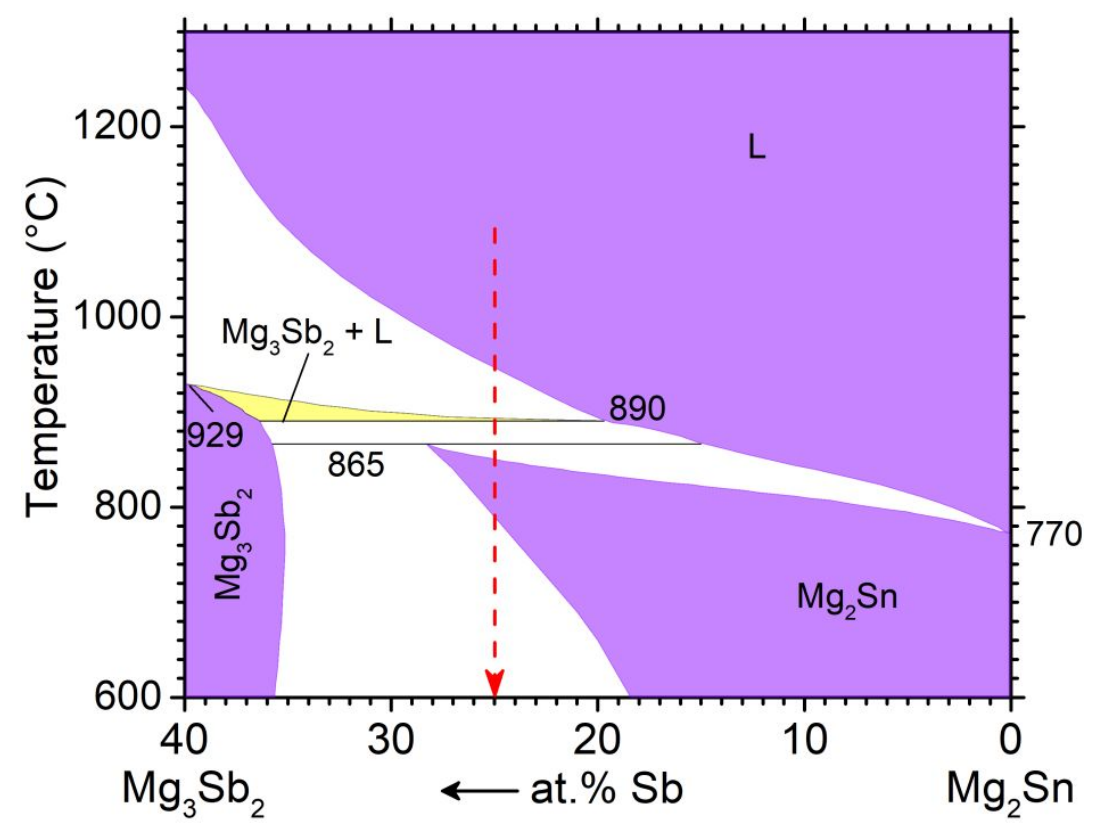

Figure S1. The pseudo-binary phase diagram of $\left(\mathrm{Mg}_{3} \mathrm{Sb}_{2}\right)_{x}\left(\mathrm{Mg}_{2} \mathrm{Sn}\right)_{1-x}$ system showing the large solubility of $\mathrm{Mg}_{3} \mathrm{Sb}_{2}$ in $\mathrm{Mg}_{2} \mathrm{Sn}$ strongly dependent on temperature. For the composition of 25 at.\% $\mathrm{Sb}$ in this work, the red dashed line demonstrates the evolution of phase composition at equilibrium condition along the direction of decreased temperature. 


\section{Supporting Information}
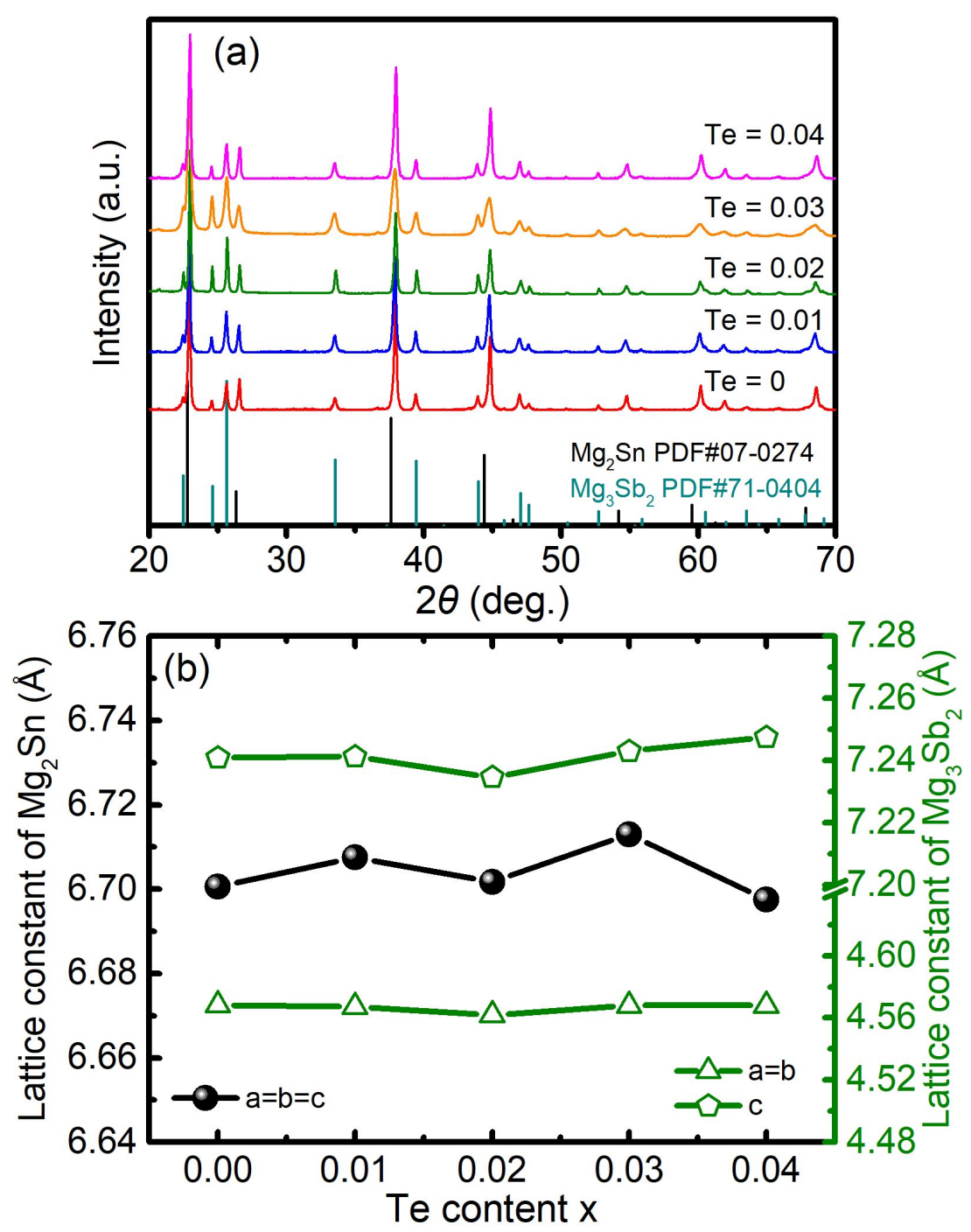

Figure S2. (a) XRD patterns of $\mathrm{Mg}_{2} \mathrm{Sn} / \mathrm{Mg}_{3} \mathrm{Sb}_{2}-x$ Te $\mathrm{HCnC}(x=0,0.01,0.02,0.03$ and 0.04) nanocomposites, which has been confirmed in the Supporting Information. (b) Te doping content dependent the lattice parameters of $\mathrm{Mg}_{3} \mathrm{Sb}_{2}$ and $\mathrm{Mg}_{2} \mathrm{Sn}$ components. 
Supporting Information

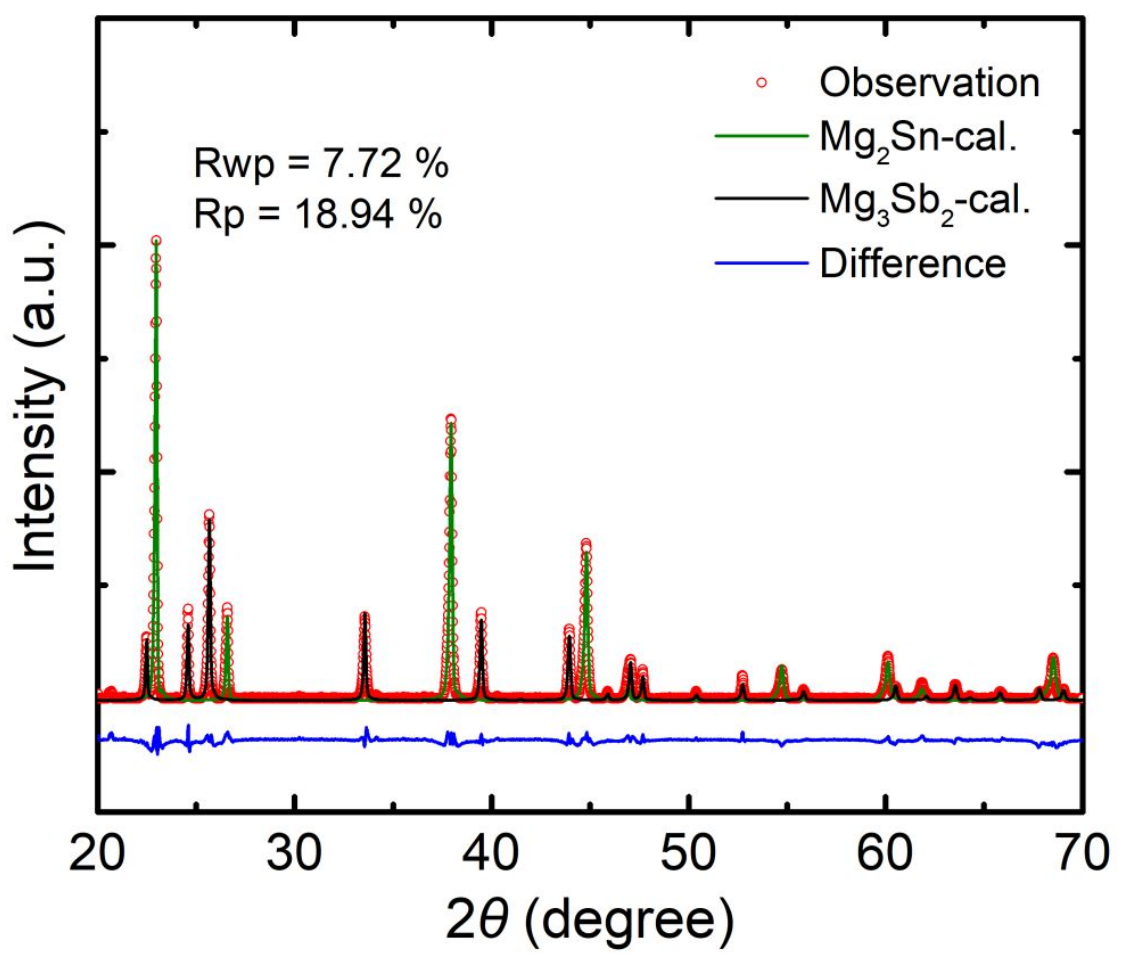

Figure S3. Rietveld refinement of powder XRD pattern for the $\mathrm{Mg}_{3} \mathrm{Sb}_{2} / \mathrm{Mg}_{2} \mathrm{Sn}-0.02$ Te HCnC sample. 


\section{Supporting Information}
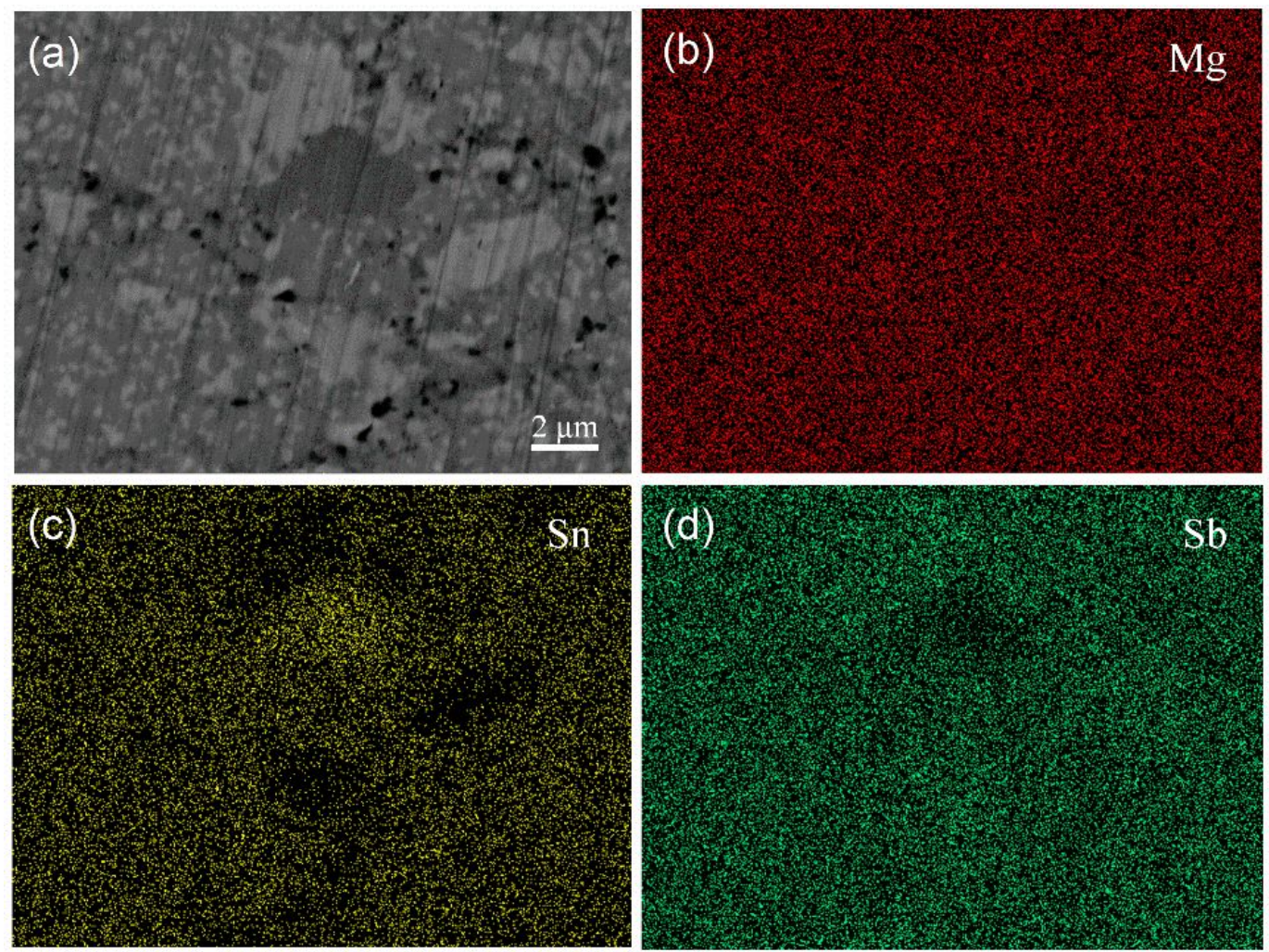

Figure S4. The element mapping of the $\mathrm{Mg}_{2} \mathrm{Sn} / \mathrm{Mg}_{3} \mathrm{Sb}_{2}-0.02 \mathrm{Te} \mathrm{HCnC}$ determined by EDS. (a) BSE image; (b) Mg element; (c) Sn element; (d) Sb element. 


\section{Supporting Information}
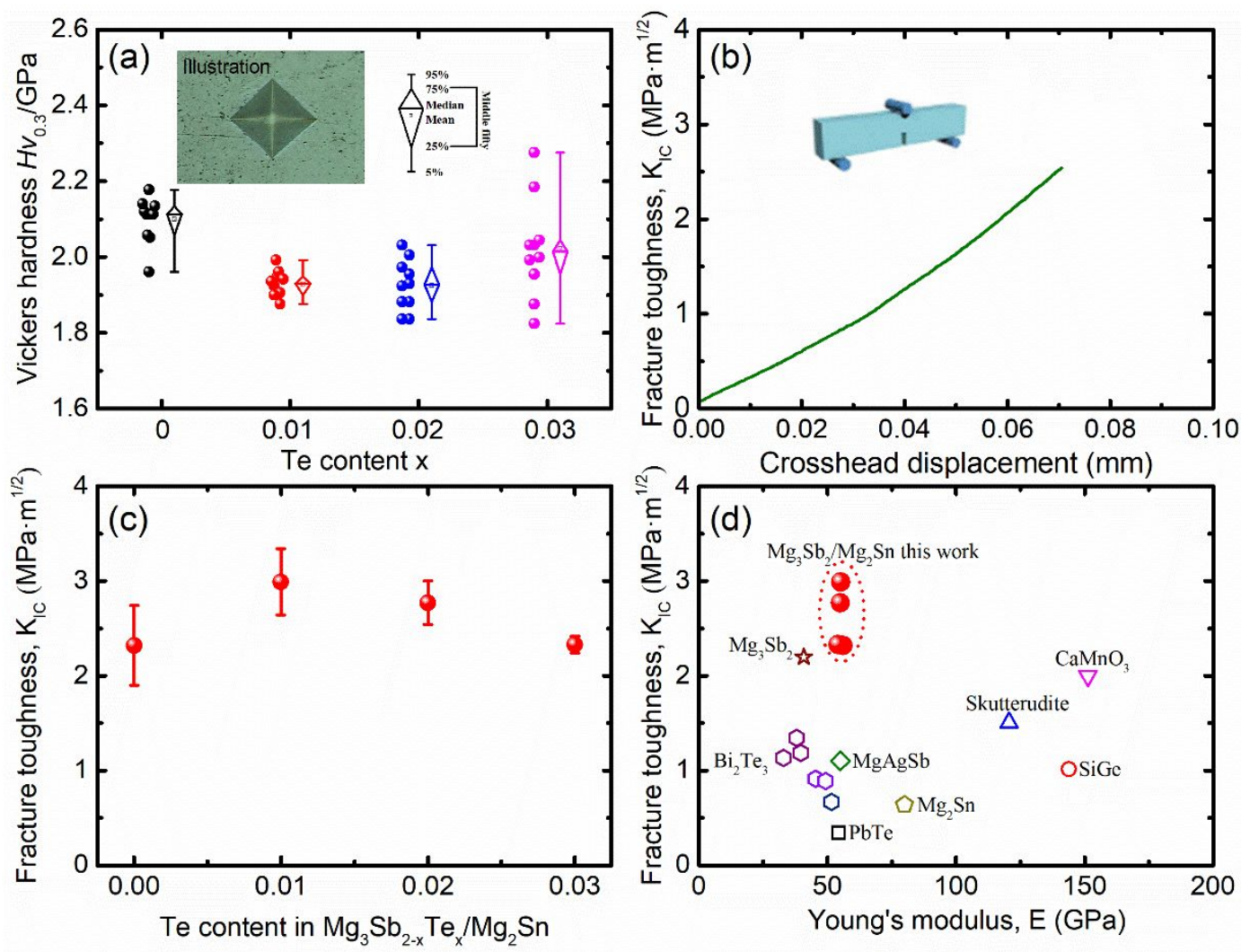

Figure S5. The measured mechanical properties of $\mathrm{Mg}_{2} \mathrm{Sn} / \mathrm{Mg}_{3} \mathrm{Sb}_{2}-x$ Te $(x=0,0.01$, 0.02 , and 0.03 ) HCnCs samples at room temperature. (a) The Te content-dependent the Vickers hardness $\left(H_{v}\right)$, the inset showing a cross-shaped indentation and crack propagation; (b) the fracture toughness-displacement curve of $\mathrm{Mg}_{2} \mathrm{Sn} / \mathrm{Mg}_{3} \mathrm{Sb}_{2}-0.02$ $\mathrm{Te} \mathrm{HCnC}$; (c) Te content-dependent the fracture toughness $\left(K_{\mathrm{IC}}\right)$; (c) fracture toughness against Young's modulus of typical thermoelectric materials. 
Supporting Information

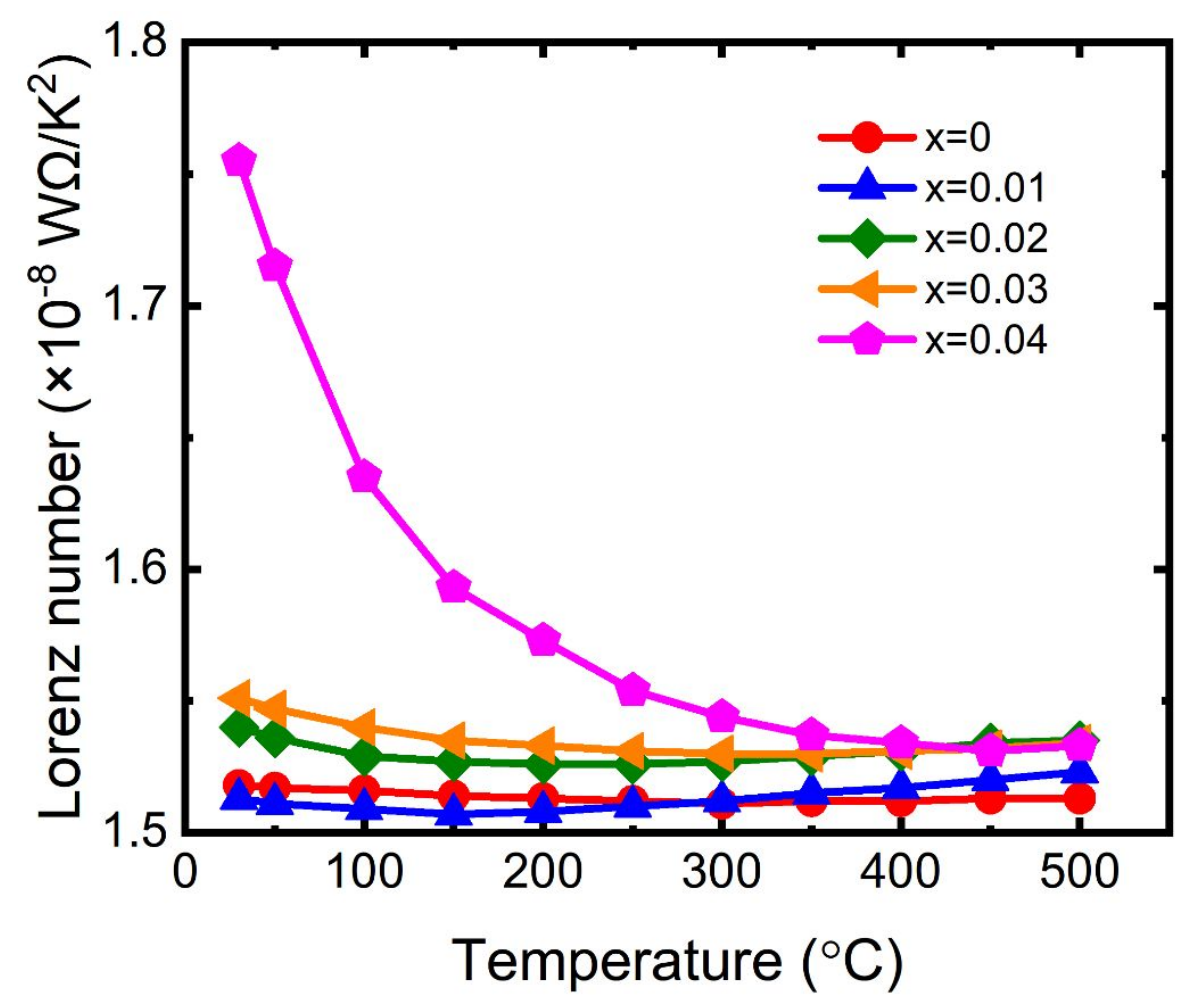

Figure S6. Calculated Lorenz number $L$ of $\mathrm{Mg}_{2} \mathrm{Sn} / \mathrm{Mg}_{3} \mathrm{Sb}_{2}-x$ Te $(x=0,0.01,0.02$, and 0.03) HCnCs. 
Supporting Information

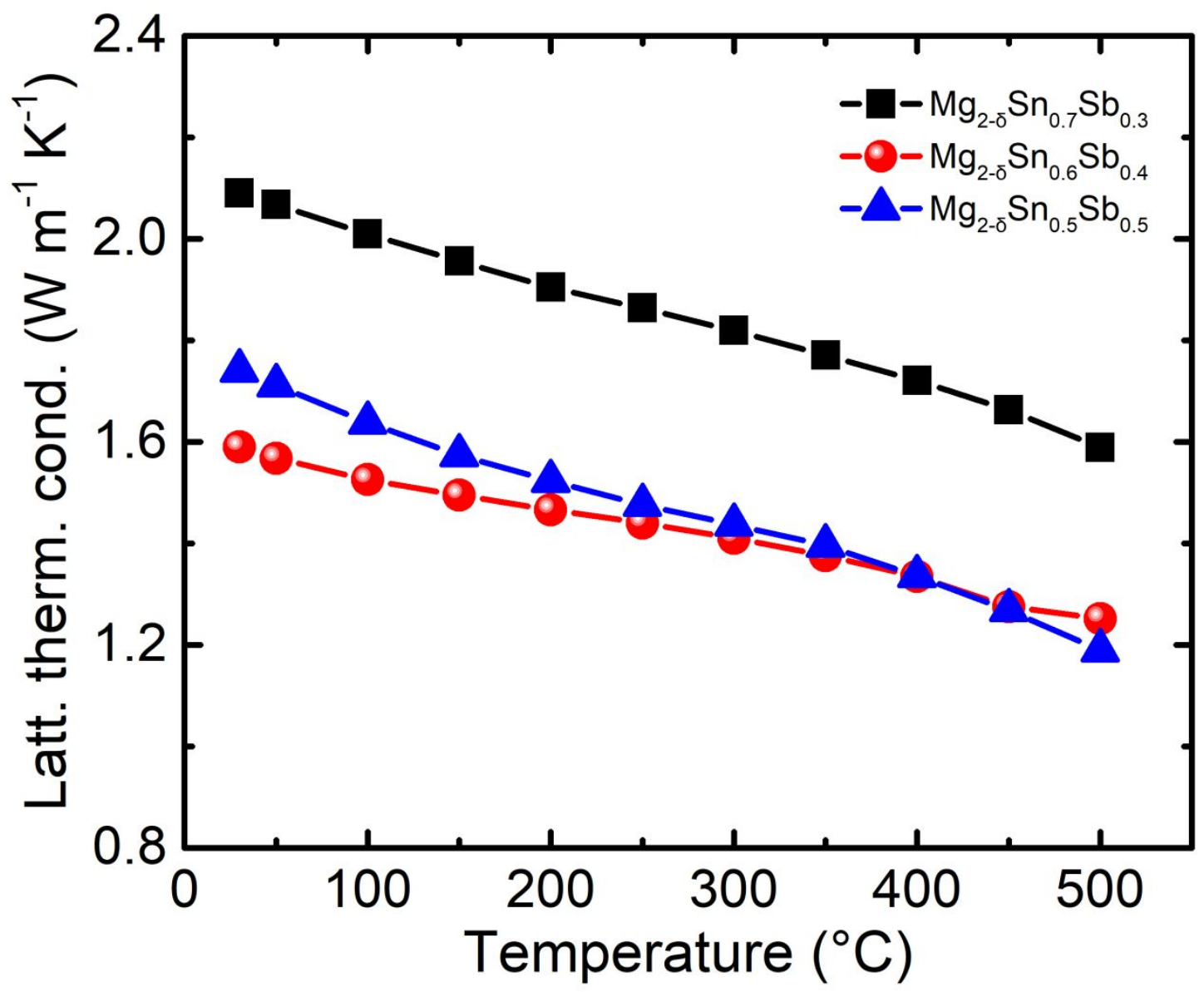

Figure S7. The experimental lattice thermal conductivities of $\mathrm{Mg}_{2-\delta} \mathrm{Sn}_{1-x} \mathrm{Sb}_{x}(x=0.3$, 0.4 , and 0.5 ) reported by the literature. ${ }^{(1)}$ 


\section{Supporting Information}

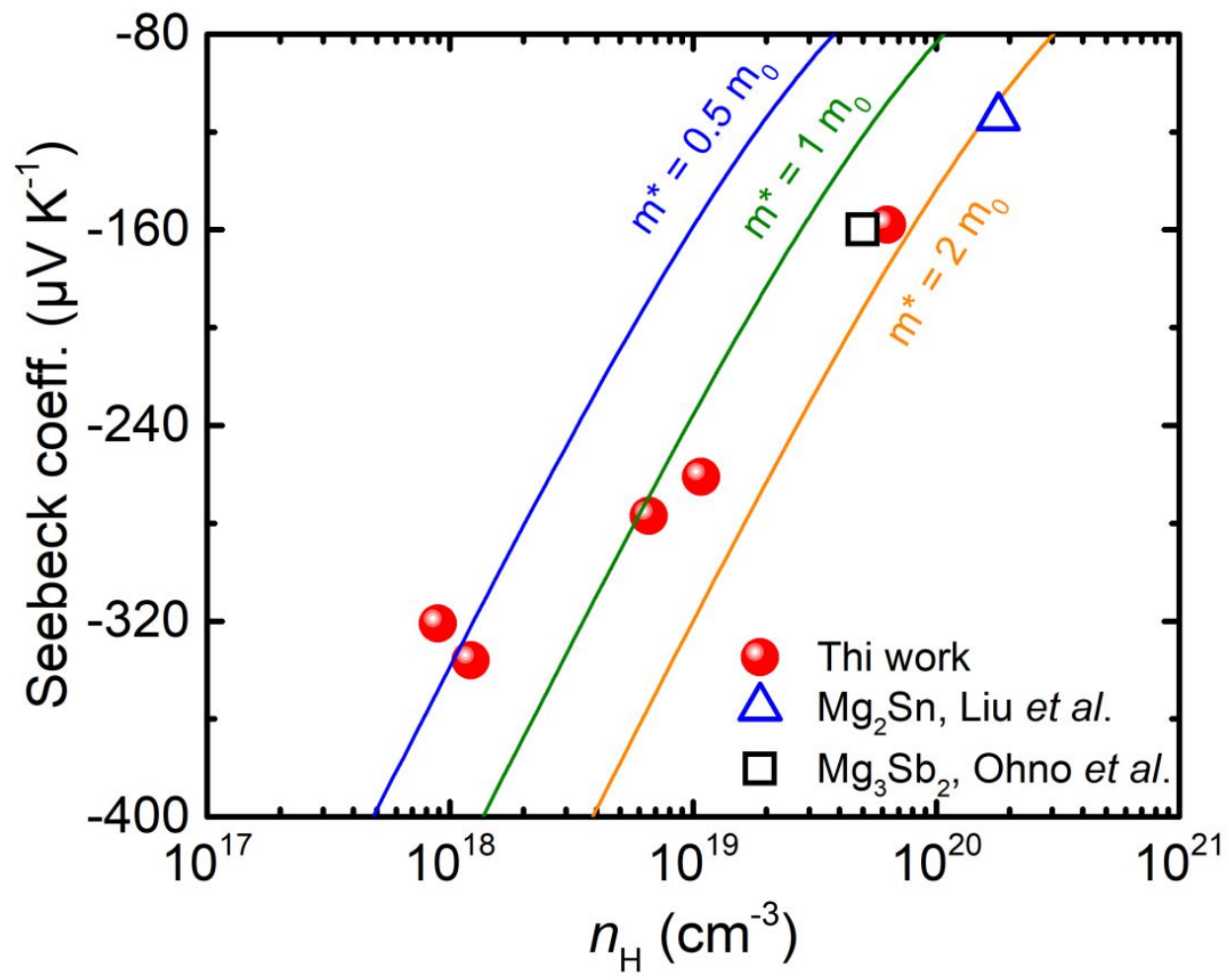

Figure S8. At room temperature $\left(30^{\circ} \mathrm{C}\right)$, calculated Pisarenko plots $\left(m^{*}=0.5,1\right.$, and $2 m_{0}$ ) based on the single parabolic band (SPB) model under acoustic phonon scattering dominating, and the measured Seebeck coefficient v.s. Hall carrier concentration, as well as the data of pure $\mathrm{Mg}_{3} \mathrm{Sb}_{2}{ }^{(16)}$ and $\mathrm{Mg}_{2} \mathrm{Sn}^{(17)}$ for comparison. 


\section{Supporting Information}

Table S1. The chemical composition (mol\%) of each scanning spot for $\mathrm{Mg}_{2} \mathrm{Sn} / \mathrm{Mg}_{3} \mathrm{Sb}_{2}-0.02 \mathrm{Te} \mathrm{HCnC}$ by EDS, in which the matrix and dispersed phase have an average composition $\mathrm{Mg}_{1.85} \mathrm{Sn}_{0.39} \mathrm{Sb}_{0.61}$ and $\mathrm{Mg}_{3.28} \mathrm{Sb}_{1.85} \mathrm{Sn}_{0.15}$, respectively.

\begin{tabular}{|c|c|c|c|c|}
\hline Area & Spots & $\mathrm{Mg}$ & $\mathrm{Sn}$ & $\mathrm{Sb}$ \\
\hline \multirow{4}{*}{ Bright } & Spot 1 & 62.01 & 2.77 & 35.22 \\
\cline { 2 - 5 } & Spot 2 & 61.81 & 3.19 & 35.01 \\
\cline { 2 - 5 } & Spot 3 & 61.64 & 2.51 & 35.85 \\
\cline { 2 - 5 } & Spot 4 & 61.7 & 3.11 & 35.19 \\
\cline { 2 - 5 } & Spot 5 & 62.8 & 2.81 & 34.39 \\
\cline { 2 - 5 } & Spot 6 & 62.84 & 3.01 & 34.15 \\
\hline \multirow{4}{*}{ Dark } & Spot 1 & 64.29 & 14.14 & 21.57 \\
\cline { 2 - 5 } & Spot 2 & 65.39 & 14.03 & 20.58 \\
\cline { 2 - 5 } & Spot 3 & 66.97 & 13.48 & 19.56 \\
\cline { 2 - 5 } & Spot 4 & 63.6 & 13.74 & 22.56 \\
\cline { 2 - 5 } & Spot 5 & 64.28 & 12.84 & 22.88 \\
\cline { 2 - 5 } & Spot 6 & 65.12 & 12.9 & 21.98 \\
\hline
\end{tabular}




\section{Supporting Information}

Table S2. The electrical and thermal transport parameters of $\mathrm{Mg}_{2} \mathrm{Sn} / \mathrm{Mg}_{3} \mathrm{Sb}_{2}-x \mathrm{Te}$ $\mathrm{HCnCs}$ at room temperature.

\begin{tabular}{|c|c|c|c|}
\hline $\begin{array}{c}\text { Te content } \\
(x)\end{array}$ & $\begin{array}{c}\mu \\
\left(\mathrm{cm}^{2} \mathrm{~V}^{-1} \mathrm{~s}^{-1}\right)\end{array}$ & $\begin{array}{c}\kappa_{\text {lat }} \\
\left(\mathrm{W} \mathrm{m}^{-1} \mathrm{~K}^{-1}\right)\end{array}$ & $\begin{array}{c}\mu / \kappa_{\text {lat }} \\
\left(\times 10^{-3} \mathrm{~m}^{3} \mathrm{~K} \mathrm{~V}^{-1} \mathrm{~J}^{-1}\right)\end{array}$ \\
\hline 0 & 2.3 & 1.11 & 0.21 \\
\hline 0.01 & 11.82 & 1.14 & 1.04 \\
\hline 0.02 & 13.25 & 1.09 & 1.22 \\
\hline 0.03 & 8.71 & 1.08 & 0.81 \\
\hline 0.04 & 0.93 & 1.04 & 0.09 \\
\hline
\end{tabular}




\section{Supporting Information}

\section{References}

(1) Y.B. Zhu, Z.J. Han, F. Jiang, E.T. Dong, B.P. Zhang, W.Q. Zhang, W.S. Liu, Thermodynamic Criterions of the Thermoelectric Performance Enhancement in $\mathrm{Mg}_{2} \mathrm{Sn}$ through the Self-compensation Vacancy, Mater. Today Phys. 16 (2021), 100327.

(2) M.K. Habibi, M. Gupta, S.P. Joshi, Size-effects in Textural Strengthening of Hierarchical Magnesium Nano-composites, Mater. Sci. Eng. A 556 (2012), 855.

(3) L.D. Zhao, B.P. Zhang, J.F. Li, M. Zhou, W.S. Liu, J. Liu, Thermoelectric and Mechanical Properties of Nano-SiC-dispersed $\mathrm{Bi}_{2} \mathrm{Te}_{3}$ Fabricated by Mechanical Alloying and Spark Plasma Sintering, J. Alloys Compd. 455 (2008), 259.

(4) G. Li, K.R. Gadelrab, T. Souier, P.L. Potapov, G. Chen, M. Chiesa, Mechanical Properties of $\mathrm{Bi}_{x} \mathrm{Sb}_{2-x} \mathrm{Te}_{3}$ Nanostructured Thermoelectric Material, Nanotechnology 23 (2012), 065703.

(5) G.D. Li, U. Aydemir, B. Duan, M.T. Agne, H.T. Wang, M. Wood, Q.J. Zhang, P.C. Zhai, W.A. Goddard, G.J. Snyder, Micro- and Macromechanical Properties of Thermoelectric Lead Chalcogenides, ACS Appl. Mater. Interfaces, 9 (2017), 40488.

(6) Z.H. Liu, J. Mao, J.H. Sui, Z.F. Ren, High Thermoelectric Performance of $\alpha-\mathrm{MgAgSb}$ for Power Generation, Energy Environ. Sci. 11 (2018), 23.

(7) G. Rogl, P. Rogl, How Nanoparticles can Change the Figure of Merit, ZT, and Mechanical Properties of Skutterudites, Mater. Today Phys. 3 (2017), 48.

(8) A.C. Kallel, G. Roux, C.L. Martin, Thermoelectric and Mechanical Properties of a Hot Pressed Nanostructured N-type $\mathrm{Si}_{80} \mathrm{Ge}_{20}$ alloy, Mater. Sci. Eng. A 564 (2013), 65 .

(9) A. Kosuga, S. Urata, K. Kurosaki, S. Yamanaka, R. Funahashi, Mechanical Properties of $\mathrm{Ca}_{0.9} \mathrm{Yb}_{0.1} \mathrm{MnO}_{3} / \mathrm{Ag}$ Composites for N-type Legs of Thermoelectric Oxide devices, Jpn. J. Appl. Phys. 47 (2008), 6399.

(10) G.C. Hernandez, M. Yasseri, S. Ayachi, J.D. Boor, E. Müller, Hardness and Fracture Toughness of Solid Solutions of $\mathrm{Mg}_{2} \mathrm{Si}$ and $\mathrm{Mg}_{2} \mathrm{Sn}$, Semiconductors 53 (2019), 1831.

(11) R. Shu, Y.C. Zhou, Q. Wang, Z.J. Han, Y.B. Zhu, Y. Liu, Y.X. Chen, M. Gu, 


\section{Supporting Information}

W. Xu, Y. Wang, W.Q. Zhang, L. Huang, W.S. Liu, $\mathrm{Mg}_{3+\delta} \mathrm{Sb}_{x} \mathrm{Bi}_{2-x}$ Family: a Promising Substitute for the State-of-the-art N-type Thermoelectric Materials near Room Temperature, Adv. Funct. Mater. 29 (2018), 1807235.

(12) V.M. Prokhorov, G.I. Pivovarov, Detection of Internal Cracks and Ultrasound Characterization of Nanostructured $\mathrm{Bi}_{2} \mathrm{Te}_{3}$-based thermoelectrics via Acoustic Microscopy, Ultrasonics 51 (2011), 715.

(13) H.M. Ledbetter, N.V. Frederick, M.W. Austin, Elastic-constant Variability in Stainless-steel 304, J. Appl. Phys. 51 (1980), 305.

(14) J.B. Wachtman, W.R. Cannon, M.J. Matthewson, Mechanical Properties of Ceramics, John Wiley \& Sons, 2009.

(15) Z.D. Guan, Z.T. Zhang, J.S. Jiao, Physical Properties of Inorganic Materials (In Chinese), Tsinghua University Press, Beijing, 2009.

(16) S. Ohno, K. Imasato, S. Anand, H. Tamaki, S.D. Kang, P. Gorai, H.K. Sato, E.S. Toberer, T. Kanno, G.J. Snyder, Phase Boundary Mapping to Obtain N-type $\mathrm{Mg}_{3} \mathrm{Sb}_{2}$-based Thermoelectrics, Joule 2 (2018), 141.

(17) W. S. Liu, H. S. Kim, S. Chen, Q. Jie, B. Lv, M. L. Yao, Z. S. Ren, C. P. Opeil, S. Wilson, C. W. Chu, Z. F. Ren, N-type Thermoelectric Material $\mathrm{Mg}_{2} \mathrm{Sn}_{0.75} \mathrm{Ge}_{0.25}$ for High Power Generation, Proc. Natl. Acad. Sci. USA 112 (2015), 3269. 